\title{
Increased fatigue strength of partially stabilized zirconia achieved by shot peening
}

\author{
Koji TAKAHASHIa*, Kae IWANAKA ${ }^{a}$, Hitonobu KOIKEa
}

aYokohama National University, 79-5 Tokiwadai, Hodogaya, Yokohama 240-8501, Japan

*Corresponding author:

Prof. Koji Takahashi

Professor, Faculty of Engineering,

Yokohama National University,

79-5, Tokiwadai, Hodogaya, Yokohama, 240-8501, Japan.

E-mail: takahashi-koji-ph@ynu.ac.jp

Phone: 81-45-339-4017

Fax: 81-45-339-4024 


\section{Increased fatigue strength of partially stabilized zirconia achieved by shot peening}

The effects of shot peening on the fatigue strength of partially stabilized zirconia (PSZ) were studied. Smooth specimens and specimens containing a surface pre-crack with depths in the range $35-110 \mu \mathrm{m}$ were subjected to shot peening. The cyclic fatigue tests were performed using a three-point bending setup. Shot peening introduced compressive residual stresses on the specimens and improved their fatigue strengths. The shot peened specimens with pre-crack depths $\leq 50 \mu \mathrm{m}$ fractured outside the pre-crack area and exhibited considerably high fatigue limits, equivalent to those of the shot peened smooth specimens. Therefore, the pre-cracks with depths $\leq 50 \mu \mathrm{m}$ could be rendered harmless by shot peening, which was confirmed by the theoretical estimations based on fracture mechanics.

Keywords: partially stabilized zirconia; shot peening; fatigue strength; residual stress; fracture mechanics

\section{Introduction}

Zirconia can exhibit superior fracture toughness than other ceramics due to the stress induced transformation from the tetragonal to the monoclinic phase, ${ }^{1}$ which makes it suitable for applications such as mechanical components and dental materials. The mechanical components are subjected to repeated stress during their use. Accordingly, it is important to assess the fatigue strength characteristics of zirconia, and many studies have been carried out in this regard..$^{2-5}$ In the process of manufacturing of ceramic components, machining procedures such as grinding which may initiate the formation of surface cracks, are carried out. This leads to reduction in the fatigue strength if the size of the crack is larger than the acceptable size..$^{3,4}$ 
Shot peening (SP) is a surface treatment process that involves impacting a surface with shots.

The main purpose of shot peening is to increase the fatigue strength and prevent the stress corrosion cracking of metals. It has been reported that shot peening on the steels containing cracklike surface defects improves the fatigue limit by increasing the acceptable defect size, in spring steels, ${ }^{6-9}$ low-alloy steels ${ }^{10}$ and carbon steels. ${ }^{11,12}$ In other words, the surface defects are rendered harmless by shot peening, from the viewpoint of the fatigue limit.

Recent studies have shown that shot peening introduces compressive residual stresses near the surfaces of ceramics such as silicon nitride, ${ }^{13-16}$ alumina,,${ }^{13,17}$ and zirconia. ${ }^{18-20}$ Moon et al. carried out shot peening on alumina and silicon nitride and reported that the fracture resistance of the subsurface regions increased. ${ }^{13}$ Pfeiffer and Frey reported that large compressive residual stresses up to $2000 \mathrm{MPa}$ could be introduced into the near surface of alumina and silicon nitride ceramics by shot peening. ${ }^{14}$ They showed that the static and cyclic load capacities increased by a factor of four. ${ }^{14}$ Takahashi et al. reported that the combination of shot peening and crack healing increased the static contact strength of silicon nitride ${ }^{15,16}$ and alumina composites ${ }^{17}$. Ito et al. reported that the flexural strength and the Weibull coefficient of partially stabilized zirconia (PSZ) could be improved by the beneficial effects of soft shot peening using aluminium shots. ${ }^{18}$ Shukla and Lawrence applied micro-shot peening using glass beads and found that the method was effective in increasing the fracture toughness of zirconia-advanced ceramics. ${ }^{19}$ Takahashi et al. reported that a compressive residual stress of $1800 \mathrm{MPa}$ introduced in PSZ can improve both the wear 
resistance ${ }^{21}$ and the fracture toughness. ${ }^{20}$ It was also shown that the flexural strengths of the precracked specimens were significantly improved and the pre-cracks with a depth less than $60 \mu \mathrm{m}$ were rendered harmless by shot peening. ${ }^{20}$ However, the effects of shot peening on the cyclic fatigue strength of zirconia have not yet been studied.

This study was carried out to analyse the effects of shot peening on the cyclic fatigue strength of PSZ containing a surface pre-crack. Smooth specimens and specimens containing a surface pre-crack were subjected to shot peening and cyclic fatigue tests were performed. The depth of the pre-crack that can be rendered harmless by shot peening was studied in terms of the cyclic fatigue limit.

\section{Materials and methods}

\section{Specimen preparation}

The PSZ ceramic used in this study was ZR1 (Japan Fine Ceramics Center), which consists of 3 mol\% $\mathrm{Y}_{2} \mathrm{O}_{3}$ as a stabilizer. Figure 1(a) shows the shape and the dimensions of the specimens used for the cyclic fatigue tests. The tensile surface of the specimen ( $4 \mathrm{~mm}$ wide side) was precision polished to achieve a mirror-finish. These specimens are referred to as the 'smooth' specimens. Pre-cracks were introduced at the centre of the tensile surface of the smooth specimen by Vickers indentation and these specimens are referred to as the 'pre-cracked' specimens. Figure 1(b) shows the optical micrograph of the surface of the pre-cracked specimen. The Vickers indentation loads of 30,50 , and $100 \mathrm{~N}$ with a loading time of $20 \mathrm{~s}$ resulted in surface crack lengths $(2 c)$ of 
approximately 80,110 , and $250 \mu \mathrm{m}$, respectively. The aspect ratio $(a / c)$ of the pre-crack was 0.9 . Thus, the pre-crack depths (a) were approximately 35, 50, and $110 \mu \mathrm{m}$, respectively. Five specimens were used for the measurements of the Vickers hardness (HV). The average values of the Vickers hardness for the SP and the non-SP specimens were $1310 \pm 6.3$ and $1290 \pm 13.3$, respectively. We believe that the hardness increased due to the plastic deformation near the surface layer.

[Figure 1 near here]

\section{Shot peening procedure and measurement of the residual stress}

We performed shot peening on the surfaces of the smooth and the pre-cracked specimens using a direct-pressure system. The specimens subjected to shot peening are referred to as 'smooth + SP' specimens and 'pre-crack + SP' specimens. Table 1 lists the conditions used for the shot peening. Commercial $\mathrm{ZrO}_{2}$ beads (TZ-B180, TOSOH Co. Ltd., Japan) with a diameter of $180 \mu \mathrm{m}$ and Vickers hardness of $1150 \mathrm{HV}$ were used as the shot material.

The residual stresses on the surfaces of the non-SP and SP specimens were measured using the X-ray diffraction (XRD) method with a $\mathrm{Cu}-\mathrm{K} \alpha$ beam $\mathrm{X}$-ray spectrum. The details of the measurement of the residual stress are explained in the literature. ${ }^{20} \mathrm{~A}$ large compressive residual stress of approximately $1400 \mathrm{MPa}$ was introduced on the surface of the PSZ specimen, reaching a maximum of $1800 \mathrm{MPa}$ at a depth of $20 \mu \mathrm{m} .{ }^{20}$ As the depth increased to $50 \mu \mathrm{m}$, the compressive residual stress decreased to $100 \mathrm{MPa} .{ }^{20}$ The depth of the compressive residual stress is important 
because the pre-crack size rendered harmless by shot peening is related to the depth of the compressive stress layer. The large compressive residual stress was induced by the local plastic deformation and the transformation of zirconia from the tetragonal to the monoclinic phase. ${ }^{20}$ The surface textures before and after shot peening were observed using optical microscopy and scanning probe microscopy (SPM) techniques.

[Table 1 near here]

\section{Measurement of cyclic fatigue strength}

The cyclic bending fatigue tests were carried out using a hydraulic testing machine with a stress ratio $R=0.1$ and a nominal frequency of $10 \mathrm{~Hz}$, at room temperature and room humidity by the three-point bending method. The span length for the three-point bending test was $16 \mathrm{~mm}$, which was identical to that of the previous study. ${ }^{20}$ The origins of the fractures of all the tested specimens were observed using an optical microscope and a scanning electron microscope (SEM).

\section{Results and discussion}

\section{Surface texture after shot peening}

Figure 2 shows the optical micrographs of the surfaces of the smooth and the smooth + SP specimens. The surface roughness was determined by the maximum height of the profile $\left(R_{\mathrm{y}}\right)$ according to a profilometer scan of the specimen surface. The average values of $R_{\mathrm{y}}$ for five scans were $0.36 \pm 0.04$ and $0.47 \pm 0.07 \mu \mathrm{m}$ for the smooth and the smooth + SP specimens, respectively. 
The surface roughness after shot peening was slightly higher due to the plastic deformation caused by the impact of the shot media. Figure 3 shows the SPM images of the surfaces of the smooth and the smooth + SP specimens, respectively. Nano-sized dimples were observed on the surface of the smooth + SP specimen, instead of the scratch marks on the surface of the smooth specimen. The heights of the dimples were in the range of $30-50 \mathrm{~nm}$, and they had a negligible effect on the fatigue strength, as discussed in the next section.

[Figure 2 near here]

[Figure 3 near here]

\section{Effect of shot peening on the cyclic bending fatigue strength}

Figure 4 shows the $S$ - $N$ curves, showing the relationship between the maximum bending stress during the cyclic fatigue tests $\left(\sigma_{\max }\right)$ and the number of cycles to failure $\left(N_{\mathrm{f}}\right)$. The bending strengths for each specimen ${ }^{20}$ are also plotted in Fig. 4. The asterisks $\left(^{*}\right)$ indicate that the specimens fractured outside the pre-crack area. The arrows indicate that the specimens endured $2 \times 10^{6}$ fatigue cycles. The fatigue limit $\left(\sigma_{\mathrm{f} 0}\right)$ was defined as the maximum value of $\sigma_{\max }$ at which the specimen endured $2 \times 10^{6}$ fatigue cycles. Figure 5 shows the comparison of the values of $\sigma_{\mathrm{f} 0}$. The fatigue limit of the smooth specimens increased by $19 \%$ after shot peening. The fatigue limit of the pre-cracked specimens decreased with increase in the depth of the pre-crack. However, the values of $\sigma_{\mathrm{f} 0}$ for the pre-crack + SP specimens increased by $200-540 \%$ compared to those of the pre-cracked specimens not subjected to shot peening. Thus, shot peening is effective in increasing 
the fatigue limit of PSZ. It is surprising that the fatigue limit of the pre-crack + SP specimens with $a \cong 35$ or $50 \mu \mathrm{m}$ were close to that of the smooth specimen. Similar results have been reported for metals ${ }^{6-9,12}$ however, this is the first report with regard to ceramics.

[Figure 4 near here]

[Figure 5 near here]

\section{Experimental evaluation of the pre-crack size rendered harmless by shot peening}

Figure 6 shows the SEM micrographs of the fractured surfaces after the fatigue test. All the precracked specimens without shot peening fractured at the pre-crack region regardless of the precrack depth. The Vickers indentations were observed on the fracture surfaces. Among the precrack + SP specimens, however, those with $a \cong 110 \mu \mathrm{m}$ fractured at the pre-crack location, while those with $a \cong 35$ or $50 \mu \mathrm{m}$ fractured outside the pre-crack region. There was no crack propagation from the pre-crack in the pre-crack $+\mathrm{SP}$ specimens with $a \cong 35$ or $50 \mu \mathrm{m}$, owing to the introduction of the compressive residual stress in the near-surface region by shot peening.

If the fatigue test result of a pre-crack + SP specimen meets either one of the following two conditions, the pre-crack is considered to be rendered harmless by shot peening. ${ }^{8,9}$

Condition (a): The fatigue limit increased to more than 95\% of that of the smooth $+\mathrm{SP}$ specimen.

Condition (b): More than half of the specimens fractured outside the pre-crack zone. 
In the pre-crack + SP specimens with $a \cong 50 \mu \mathrm{m}$, two out of the three specimens fractured outside the pre-crack zone, as shown in the data with the asterisks in Fig. 4(c). Thus, based on condition (b), it can be interpreted that the pre-cracks with depths below $a \cong 50 \mu \mathrm{m}$ can be rendered harmless by shot peening.

[Figure 6 near here]

\section{Theoretical estimation of the pre-crack size rendered harmless by shot peening}

The method to evaluate the crack depth, which is rendered harmless by shot peening, is based on the stress intensity factors. Here, we demonstrate that the estimated value of the crack depth is consistent with the experimental results. It was assumed that a positive value of the stress intensity factor contributes to the propagation of the fatigue crack. The apparent range of the stress intensity factor $\left(\Delta K_{\mathrm{T}}\right)$, which is a driving force for the crack propagation is expressed as follows: ${ }^{6}$

$\Delta K_{T}=K_{\max }+K_{r}$,

where, $K_{\max }$ is the stress intensity factor induced by the maximum bending stress, calculated using the Newman-Raju equation and $K_{\mathrm{r}}$ is the stress intensity factor induced by the residual stress. ${ }^{22}$ $K_{\max }$ was determined from the maximum bending stress, $\sigma_{\max }$, corresponding to the value of $\sigma_{\mathrm{f} 0}$ of the smooth + SP specimens $\left(\sigma_{\max }=\sigma_{\mathrm{f} 0}=950 \mathrm{MPa}\right)$. The equations of American Petroleum Institute Recommended Practice (API RP) 579 were used to determine the value of $K_{\mathrm{r}}$ for the surface cracks. ${ }^{23}$ The stress intensity factor for a semi-elliptical crack is expressed as follows.

$K_{r}=\left[G_{0} \sigma_{0}+G_{1} \sigma_{1}\left(\frac{a}{t}\right)+G_{2} \sigma_{2}\left(\frac{a}{t}\right)^{2}+G_{3} \sigma_{3}\left(\frac{a}{t}\right)^{3}+G_{4} \sigma_{4}\left(\frac{a}{t}\right)^{4}\right] \sqrt{\frac{\pi a}{Q}} f_{w}$, 
$Q=1+1.464\left(\frac{a}{c}\right)^{1.65}$

$f_{w}=\left[\sec \left(\frac{\pi c}{2 W}\right) \sqrt{\frac{a}{t}}\right]^{1 / 2}$

where, $G_{0}$ to $G_{4}$ represent the influence coefficients for a semi-elliptical crack according to API RP 579. $W$ and $t$ are the width and the thickness of the specimens ( $W=4 \mathrm{~mm}$ and $t=3 \mathrm{~mm})$. The coefficients, $\sigma_{0}$ to $\sigma_{4}$, are obtained by the fourth-order polynomial curve fitting of the residual stress distribution, using the equation:

$\sigma(x)=\sigma_{0}+\sigma_{1}\left(\frac{x}{t}\right)+\sigma_{2}\left(\frac{x}{t}\right)^{2}+\sigma_{3}\left(\frac{x}{t}\right)^{3}+\sigma_{4}\left(\frac{x}{t}\right)^{4}$

where $x$ indicates the distance from the specimen surface in the direction of the depth. The residual stress distribution of the SP specimens ${ }^{20}$ was approximated as a fourth-order polynomial distribution. The resulting values of $K_{\max }, K_{\mathrm{r}}$ and $\Delta K_{\mathrm{T}}$, are shown in Fig. 7. The values of $K_{\mathrm{r}}$ were negative because the residual stress was compressive. The values of $\Delta K_{\mathrm{T}}$ at the deepest point and at the surface of a semi-elliptical crack are represented by $\Delta K_{\mathrm{T}, \mathrm{A}}$ and $\Delta K_{\mathrm{T}, \mathrm{C}}$, respectively.

The method for determining the size of the pre-crack which is rendered harmless is described as follows. If $\Delta K_{\mathrm{T}}$ is less than the threshold stress intensity factor range, $\Delta K_{\mathrm{th}}$, the surface crack is considered to be harmless. The values of $\Delta K_{\mathrm{th}}$ were calculated from the fatigue limits $\left(\sigma_{\mathrm{f} 0}\right)$ of the pre-cracked specimens and are shown in Fig. 8. The figure also shows the relationship between $\Delta K_{\mathrm{T}}$ and $a$. The fatigue cracks are initiated at the deepest point in the pre-crack (point A) and the values of $\Delta K_{\mathrm{T}, \mathrm{A}}$ increase with the crack depth. Thus, the intersection between $\Delta K_{\mathrm{T}, \mathrm{A}}$ and $\Delta K_{\mathrm{th}}$ gives the maximum defect size $a_{\max }$, that can be rendered harmless by shot peening. From Fig. 8 , the 
value of $a_{\max }$ was estimated to be $53 \mu \mathrm{m}$. The experimental results indicated that the surface cracks with depth $a \leq 50 \mu \mathrm{m}$ were rendered harmless by shot peening. Thus, the theoretical result obtained using fracture mechanics is consistent with our experimental result. Shot peening is therefore a useful technique for improving the fatigue strength of PSZ and rendering the detrimental surface cracks harmless.

[Figure 7 near here]

[Figure 8 near here]

\section{Conclusion}

The effects of shot peening on the fatigue strength of PSZ and the pre-crack depth that could be rendered harmless by shot peening were investigated. The following conclusions were obtained:

(1) The fatigue limits of the pre-cracked specimens after shot peening were significantly increased, by $200-540 \%$, compared to those of the pre-cracked specimens without shot peening. The compressive residual stress induced by the local plastic deformation and the transformation of zirconia from the tetragonal to the monoclinic phase contributed to the improvement in the fatigue limits.

(2) In the pre-crack $+\mathrm{SP}$ specimens with $a \cong 35$ and $50 \mu \mathrm{m}$, majority of the specimens fractured outside the pre-crack zone. Thus, according to the experimental results, the surface cracks with a depth $\leq 50 \mu \mathrm{m}$ could be rendered harmless by shot peening. 
(3) The maximum crack depth $\left(a_{\max }\right)$ that could be rendered harmless by SP was also estimated based on fracture mechanics. The value of $a_{\max }$ was found to be $53 \mu \mathrm{m}$, which was consistent with our experimental results.

(4) Shot peening is a useful surface treatment method for improving the fatigue properties of PSZ and rendering detrimental surface cracks harmless.

\section{References}

1. R. C. Garvie, R. H. Hannink and R. T. Pascoe: 'Ceramic steel?', Nature, 1975, 258, 703704.

2. T. Kawakubo and A. Goto: 'Static and cyclic fatigue of precracked ceramics at room temperature', J. Soc. Mater. Sci., Japan, 1988, 37, 939-944.

3. V. Zelizko and M. V. Swain: 'Influence of surface preparation on the rotating flexural fatigue of Mg-PSZ', J. Mater. Sci., 1988, 23, 1077-1082.

4. K. Majima, K. Amafuji, H. Nagai and K. Shoji: 'Fatigue behaviour of Y-PSZ under alternating stresses', J. Mater. Sci. Lett., 1989, 8, 183-185.

5. T. Liu, R. Matt and G. Grathwohl: 'Static and cyclic fatigue of 2Y-TZP ceramics with natural flaws', J. Eur. Ceram. Soc., 1993, 11, 133-141.

6. K. Takahashi, T. Amano, K. Ando and F. Takahashi: 'Improvement of fatigue limit by shot peening for high-strength steel containing a crack-like surface defect', Int. J. Struct. Integrity, 2011, 2, 281-292.

7. K. Takahashi, H. Okada and K. Ando: 'Effects of shot peening on the torsional fatigue limit of high-strength steel containing an artificial surface defect', Int. J. Struct. Integrity, 2012, 3, 274-284.

8. M. Nakagawa, K. Takahashi and T. Osada: 'Improvement in fatigue limit by shot peening for high-strength steel containing crack-like surface defect: influence of surface crack aspect ratio', ASME 2013 Pressure Vessels and Piping Conference. American Society of Mechanical Engineers, PVP 2013, Paris, France, V005T011A025, 7 pages.

9. J. Yasuda, K. Takahashi and H. Okada: 'Improvement of fatigue limit by shot peening for high-strength steel containing a crack-like surface defect: Influence of stress ratio', Int. J. Struct. Integrity, 2014, 5, 45-59.

10. I. Fernández-Pariente, S. Bagherifard, M. Guagliano and R. Ghelichi: 'Fatigue behavior of nitrided and shot peened steel with artificial small surface defects', Eng. Fract. Mech., 2013, 103, 2-9. 
11. J. Sakamoto, Y.-S. Lee and S.-K. Cheong: 'Effect of surface flaw on fatigue strength of shot-peened medium-carbon steel', Eng. Fract. Mech., 2015, 133, 99-111.

12. R. Fueki, K. Takahashi and K. Houjou, 'Fatigue limit prediction and estimation for the crack size rendered harmless by peening for welded joint containing a surface crack', Mater. Sci. Appl., 2015, 06, 500-510.

13. W.-J. Moon, T. Ito, S. Uchimura and H. Saka: 'Toughening of ceramics by dislocation subboundaries', Mater. Sci. Eng. A, 2004, 387-389, 837-839.

14. W. Pfeiffer W and T. Frey: 'Strengthening of ceramics by shot peening', J. Eur. Ceram. Soc., 2006, 26, 2639-2645.

15. K. Takahashi, Y. Nishio, Y. Kimura and K. Ando: 'Improvement of strength and reliability of ceramics by shot peening and crack healing', J. Eur. Ceram. Soc., 2010, 30, 3047-3052.

16. K. Takahashi and Y. Nishio: 'Improvement of the contact strength of $\mathrm{Si}_{3} \mathrm{~N}_{4} / \mathrm{SiC}$ by a combination of shot peening and crack-healing', J. Sol. Mech. Mater. Eng., 2012, 6, 41-52.

17. T. Oki, H. Yamamoto, T. Osada and K. Takahashi, 'Improvement of the contact strength of $\mathrm{Al}_{2} \mathrm{O}_{3} / \mathrm{SiC}$ by a combination of shot peening and crack-healing', J. Powder Technol., 2013, 946984, 5 pages.

18. Y. Itoh, S. Suyama and T. Fuse: 'Effect of soft shot peening on bending strength of partially stabilized zirconia', J. Ceram. Soc. Jpn., 2003, 111, 776-780.

19. P. P. Shukla and J. Lawrence: 'Micro-shot peening of zirconia-advanced ceramic: an examination of surface integrity', J. Mater. Sci., 2015, 50, 1728-1739.

20. K. Takahashi, K. Iwanaka, T. Osada and H. Koike H: 'Increase in strength of partially stabilized zirconia after shot peening', J. Mater. Eng. Perf., 2015, 24, 3573-3578.

21. H. Koike, K. Iwanaka and K. Takahashi: 'Measurement of sliding wear of shot-peened partially stabilized zirconia plate', Appl. Mech. Mater., 2014, 597, 353-357.

22. J. C. Newman Jr and I. S. Raju: 'An empirical stress-intensity factor equation for the surface crack', Eng. Fract. Mech., 1981, 15, 185-192.

23. Rp API, Fitness-for-service, American Petroleum Institute, 2000, Washington, USA.

\section{Table captions}

Table 1. Conditions used for the shot peening of PSZ.

\section{Figure Captions}

Figure 1. (a) The shape and the dimension of the specimen used in the present study (unit: $\mathrm{mm}$ ) and the schematic of the pre-crack position. (b) Optical micrograph of the surface of the precracked specimen (indentation load: $50 \mathrm{~N}$, pre-crack length $2 c \cong 110 \mu \mathrm{m}$, pre-crack depth $a \cong 50$ 
$\mu \mathrm{m})$.

Figure 2. Optical micrographs of the surfaces of the (a) smooth and the (b) smooth + SP specimens. Figure 3. SPM images and profiles of the surfaces of the (a) smooth and the (b) smooth + SP specimens

Figure 4. $S$ - $N$ curves for the following specimens: (a) Smooth, (b) Pre-cracked with $a \cong 35 \mu \mathrm{m}$, (c) Pre-cracked with $a \cong 50 \mu \mathrm{m}$, and (d) Pre-cracked with $a \cong 110 \mu \mathrm{m}$. The open and solid symbols represent the non-SP and SP specimens, respectively.

Figure 5. Comparison of the fatigue limits for the smooth specimens, and for the pre-cracked specimens with varying crack depth $(a)$.

Figure 6. SEM micrographs of the fractured surfaces obtained after the fatigue tests, showing the origin of fracture in the different specimens.

Figure 7. Distribution of the stress intensity factors as a function of the crack depth.

Figure 8 . Estimation of the maximum crack size that can be rendered harmless by shot peening. 
Table 1. Conditions used for the shot peening of PSZ.

\begin{tabular}{ll}
\hline Shot system & Direct pressure system, FDQ-2 \\
\hline Shot material & $\mathrm{ZrO}_{2}$ beads, TZ-B180 \\
\hline Shot Vickers hardness $[\mathrm{HV}]$ & 1150 \\
\hline Shot diameter $[\mu \mathrm{m}]$ & 180 \\
\hline Shot pressure $[\mathrm{MPa}]$ & 0.2 \\
\hline Projector distance $[\mathrm{mm}]$ & 100 \\
\hline Time $[\mathrm{s}]$ & 30 \\
\hline Coverage $[\%]$ & 300 \\
\hline
\end{tabular}




\section{Figures}

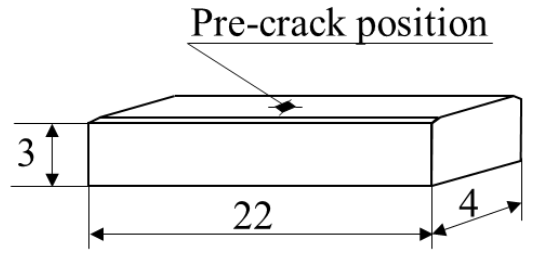

(a)

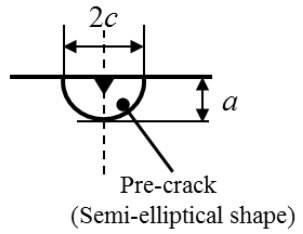

(Semi-elliptical shape)

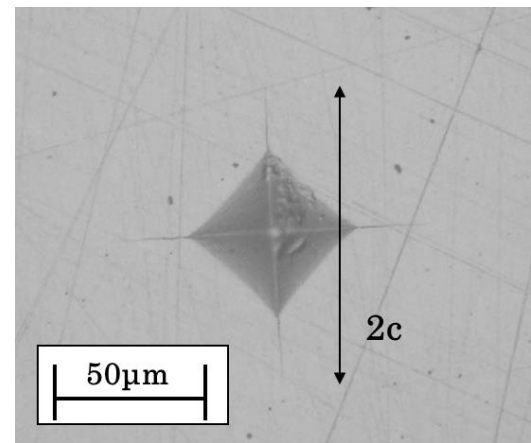

(b)

Figure 1. (a) The shape and the dimension of the specimen used in the present study (unit: $\mathrm{mm}$ ) and the schematic of the pre-crack position (b) Optical micrograph of the surface of the precracked specimen (indentation load: $50 \mathrm{~N}$, pre-crack length $2 c \cong 110 \mu \mathrm{m}$, pre-crack depth $a \cong$ $50 \mu \mathrm{m})$.

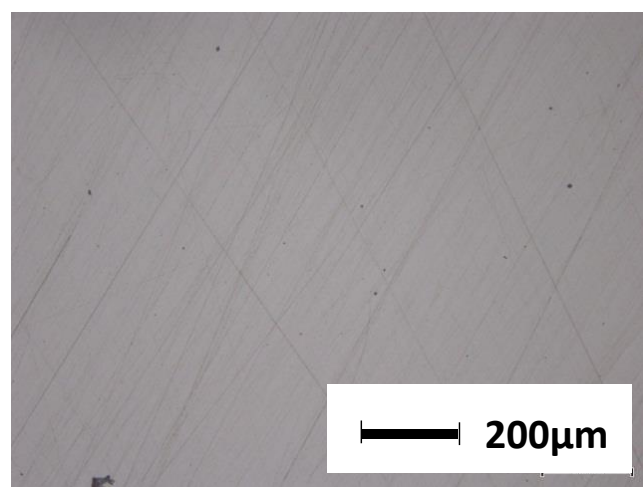

(a) Smooth

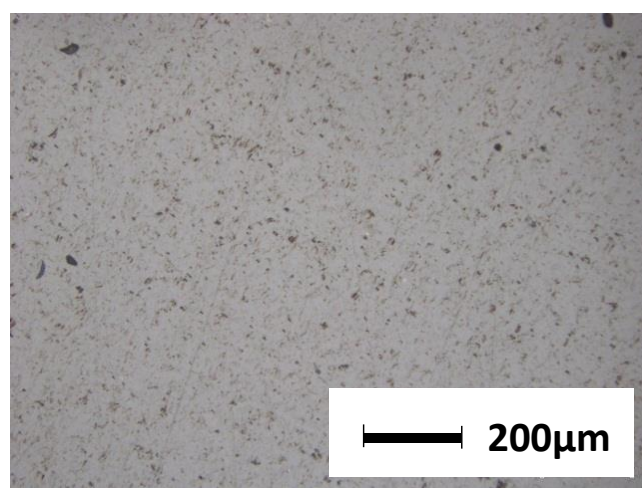

(b) Smooth $+\mathrm{SP}$

Figure 2. Optical micrographs of the surfaces of the (a) smooth and the (b) smooth + SP specimens. 

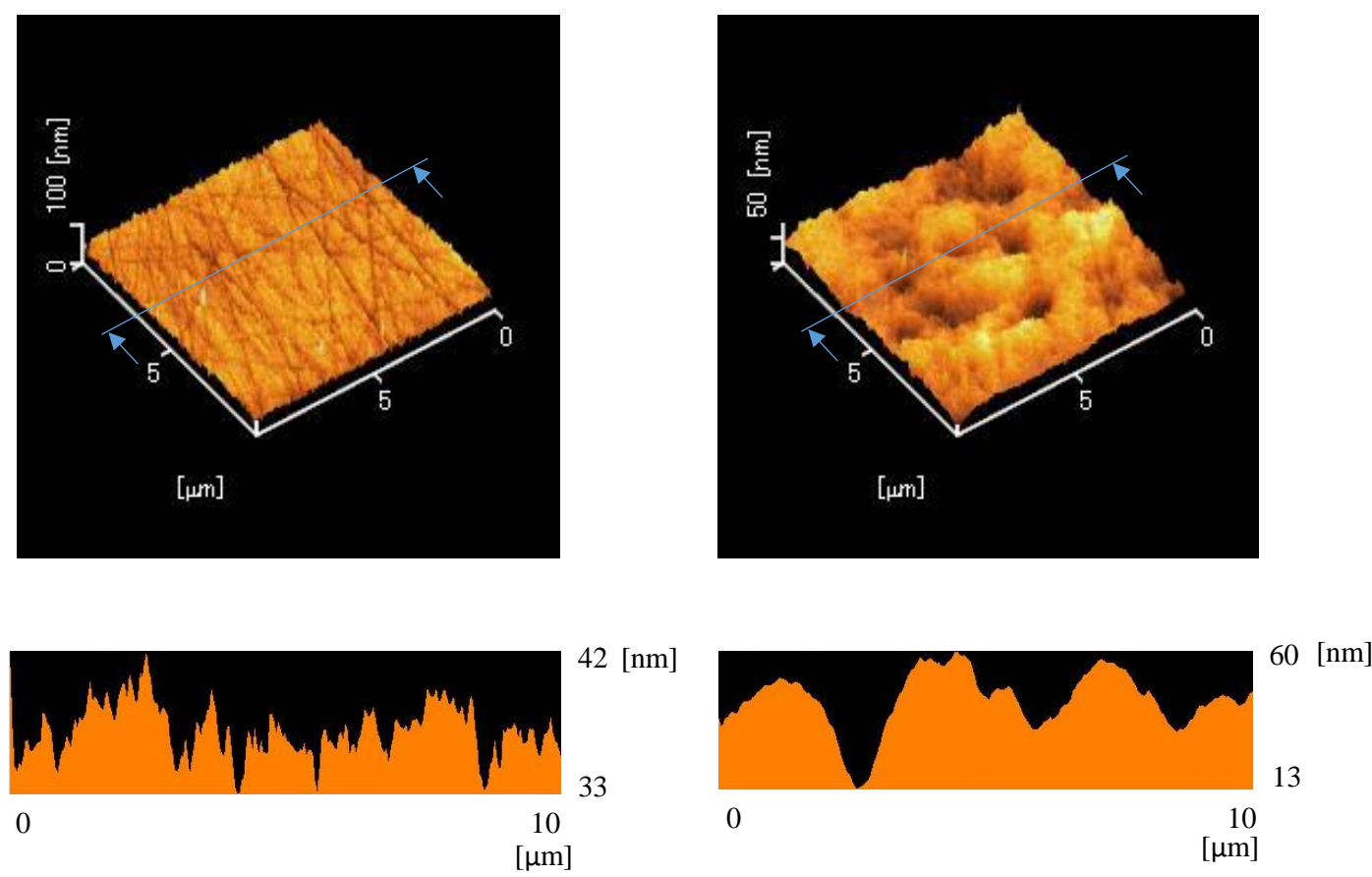

(a) Smooth

(b) Smooth $+\mathrm{SP}$

Figure 3. SPM images and profiles of the surfaces of the (a) smooth and the (b) smooth + SP specimens 


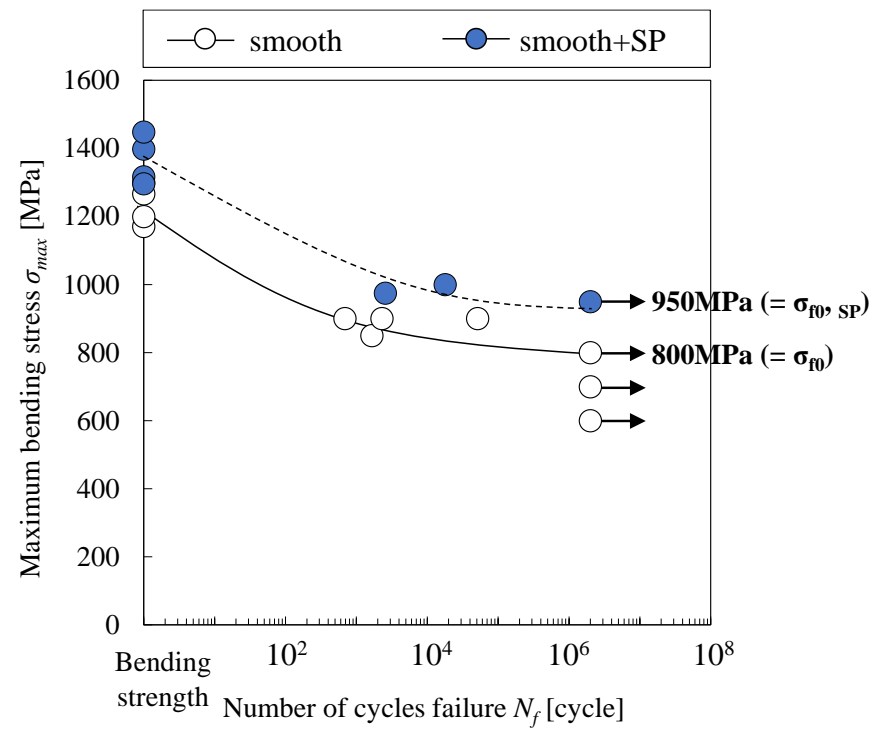

(a) smooth

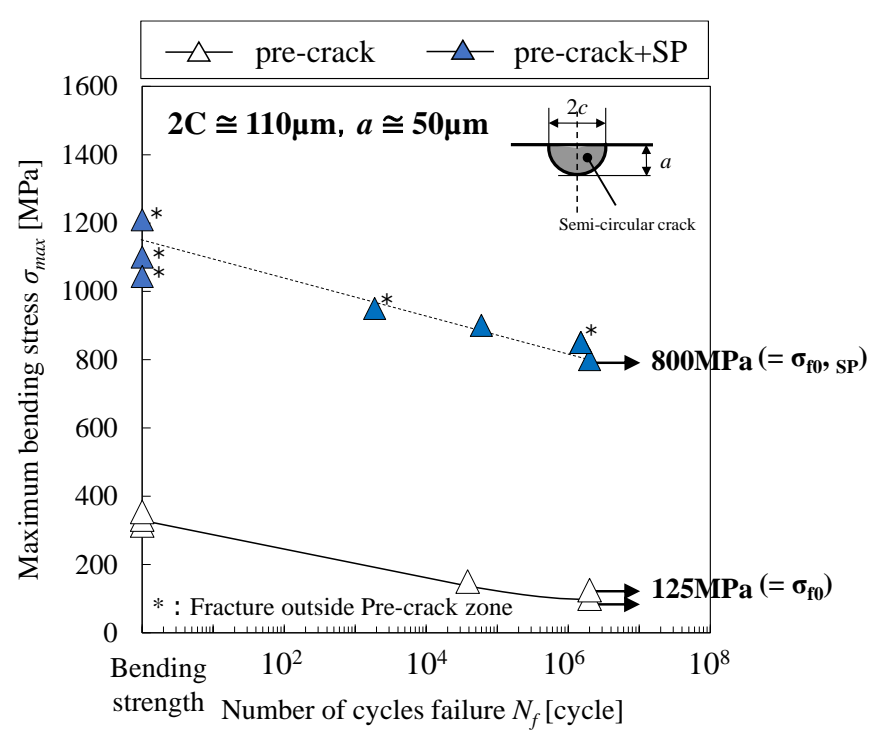

(c) $a \cong 50 \mu \mathrm{m}$

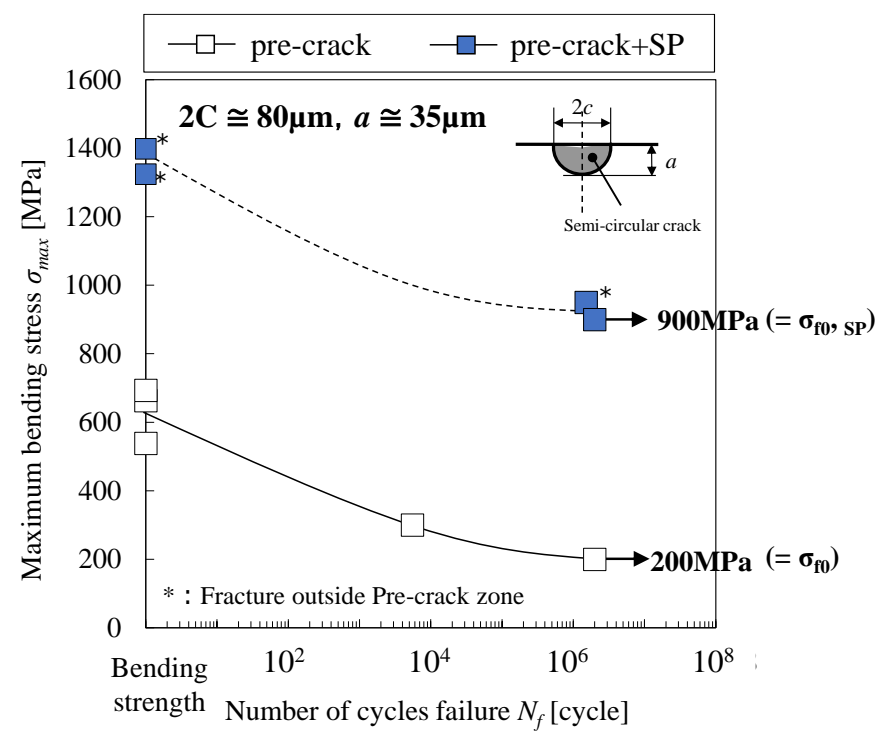

(b) $a \cong 35 \mu \mathrm{m}$

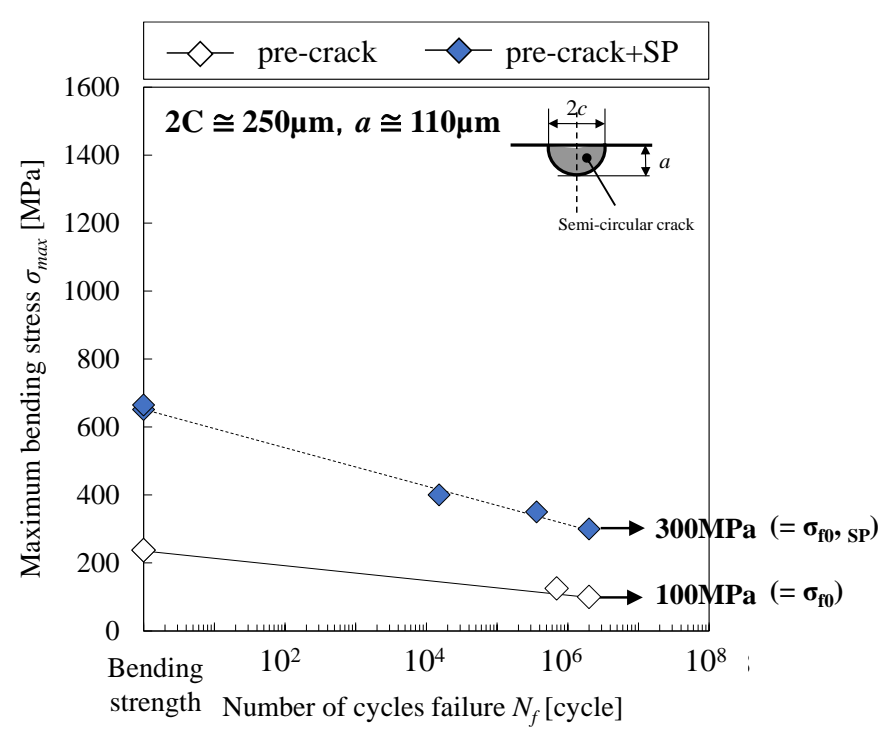

(d) $a \cong 110 \mu \mathrm{m}$

Figure 4. $S$ - $N$ curves for the following specimens: (a) Smooth, (b) Pre-cracked with $a \cong 35 \mu \mathrm{m}$,

(c) Pre-cracked with $a \cong 50 \mu \mathrm{m}$, and (d) Pre-cracked with $a \cong 110 \mu \mathrm{m}$. The open and solid symbols represent the non-SP and SP specimens, respectively. 


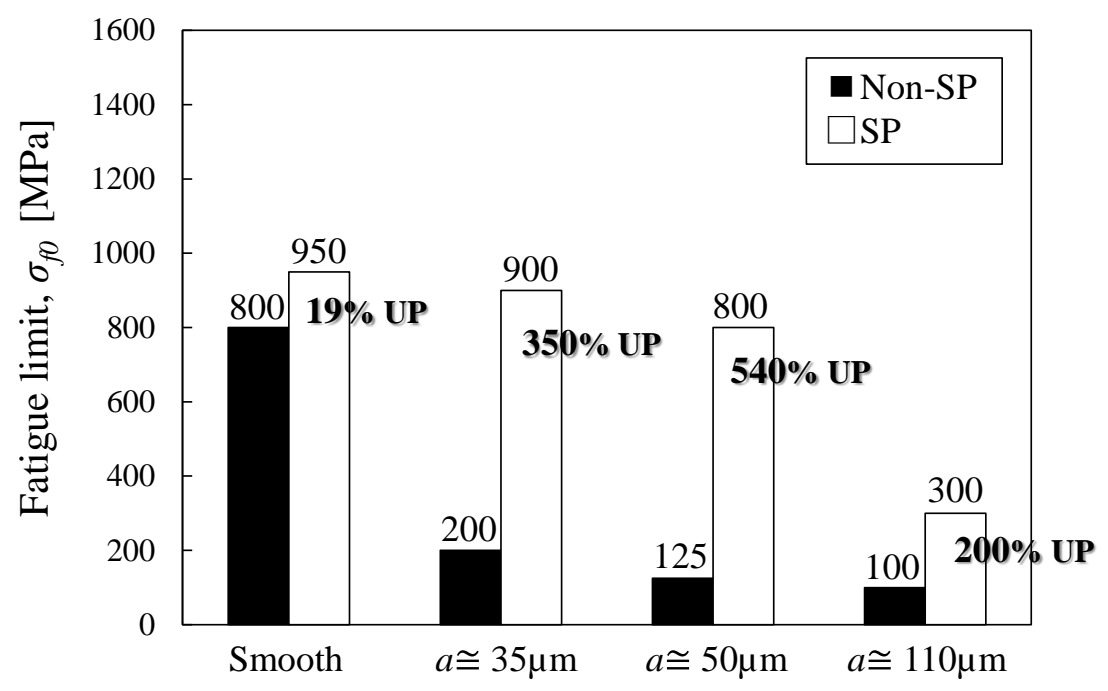

Figure 5. Comparison of the fatigue limits for the smooth specimens, and for the pre-cracked specimens with varying crack depth $(a)$. 


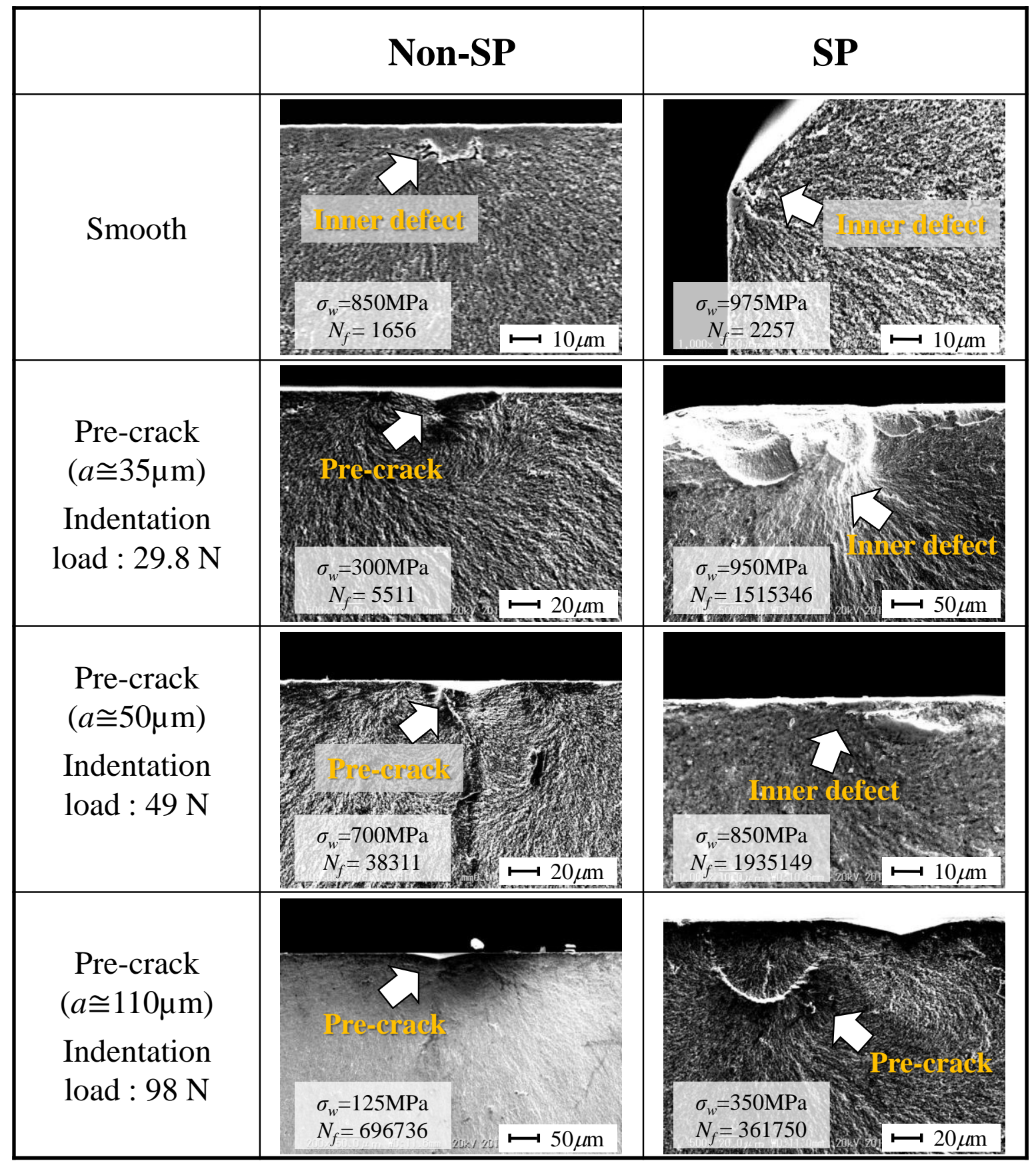

Figure 6. SEM micrographs of the fractured surfaces obtained after the fatigue tests, showing the origin of fracture in the different specimens. 


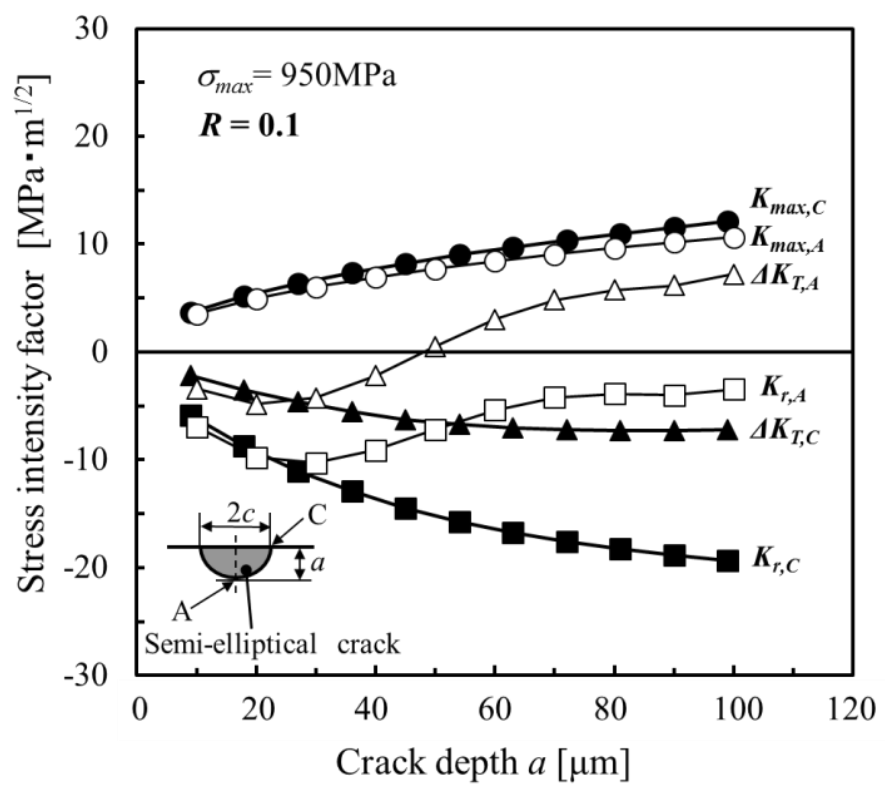

Figure 7. Distribution of the stress intensity factors as a function of the crack depth.

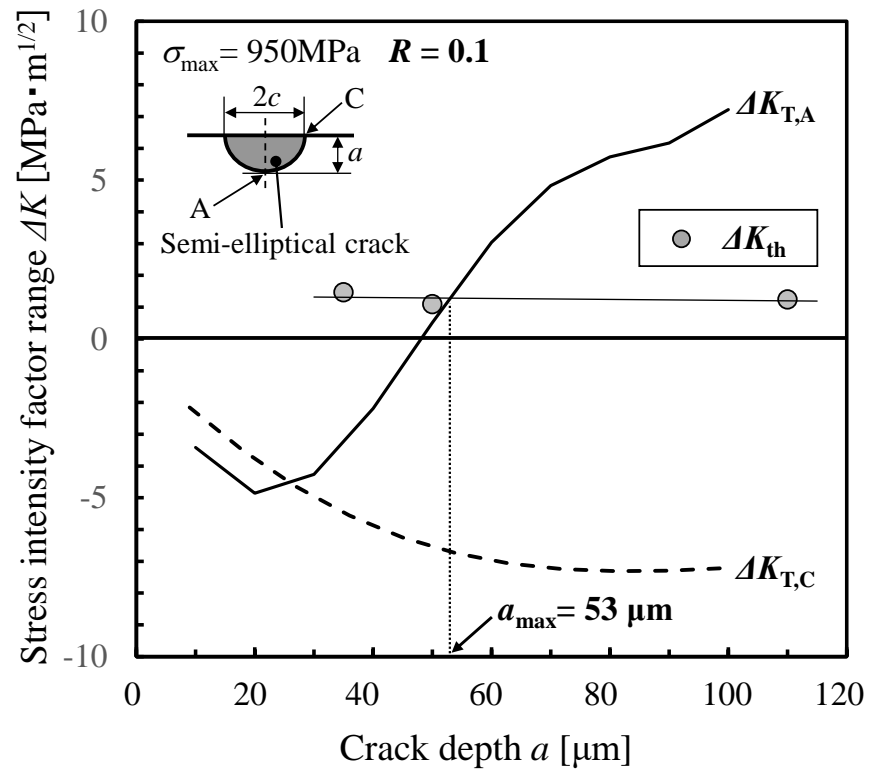

Figure 8. Estimation of the maximum crack size that can be rendered harmless by shot peening. 